ORIGINAL ARTICLE

\title{
Distinct CDH3 mutations cause ectodermal dysplasia, ectrodactyly, macular dystrophy (EEM syndrome)
}

\author{
K W Kjaer, L Hansen, G C Schwabe, A P Marques-de-Faria, H Eiberg, S Mundlos, N Tommerup, \\ T Rosenberg
}

See end of article for authors' affiliations

\section{Correspondence to:} K W Kjaer, Wilhelm Johannsen Centre for Functional Genome Research, Institute of Medical Biochemistry and Genetics, Panum Institute 24.4, 2200 Copenhagen N, Denmark; klaus@ medgen.ku.dk

Accepted for publication 18 November 2004
Background: EEM syndrome is the rare association of ectodermal dysplasia, ectrodactyly, and macular dystrophy (OMIM 225280).

Methods: We here demonstrate through molecular analysis that EEM is caused by distinct homozygous $\mathrm{CDH} 3$ mutations in two previously published families.

Results: In family 1, a missense mutation $(\mathrm{c} .965 \mathrm{~A} \rightarrow \mathrm{T}$ ) causes a change of amino acid 322 from asparagine to isoleucine; this amino acid is located in a highly conserved motif likely to affect $\mathrm{Ca}^{2+}$ binding affecting specificity of the cell-cell binding function. In family 2, a homozygous frameshift deletion (c.829delG) introduces a truncated fusion protein with a premature stop codon at amino acid residue 295, expected to cause a non-functional protein lacking both its intracellular and membrane spanning domains and its extracellular cadherin repeats $3-5$. Our mouse in situ expression data demonstrate that Cdh 3 is expressed in the apical ectodermal ridge from E10.5 to E12.5, and later in the interdigital mesenchyme, a pattern compatible with the EEM phenotype. Furthermore, we discuss possible explanations for the phenotypic differences between EEM and congenital hypotrichosis with juvenile macular dystrophy (HJMD), which is also caused by $\mathrm{CDH} 3$ mutations.

Conclusions: In summary, we have ascertained a third gene associated with ectrodactyly and have demonstrated a hitherto unrecognised role of $\mathrm{CDH} 3$ in shaping the human hand.
$\mathrm{R}$ eferring to a previously published Danish family, ${ }^{1}$ Ohdo et al first coined the term EEM syndrome to describe the rare association of ectodermal dysplasia, ectrodactyly, and macular dystrophy ${ }^{2}$ (OMIM 225280). Synonyms are Albrectsen-Svendsen syndrome or Ohdo-HirayamaTerawaki syndrome. To date five families have been reported in the literature. ${ }^{1-5}$ The ectodermal defect is characterised by hypotrichosis with sparse and short hair on the scalp, sparse and short eyebrows and eyelashes, and partial anodontia. Different degrees of absence deformities as well as syndactyly have been described, the hands often being more severely affected than the feet. The phenotypic spectrum of limb defects reported in EEM families is shown in table 1. The retinal lesion appears as a central geographic atrophy of the retinal pigment epithelium and choriocapillary layer of the macular area with coarse hyperpigmentations and sparing of the larger choroidal vessels. Autosomal recessive inheritance is supported by the presence of multiple affected individuals in a family with unaffected parents and parental consanguinity as well as an equal distribution between both sexes. However, the pathogenesis remains unknown.

We carried out a molecular study of two previously published families from Denmark ${ }^{1}$ and Brazil. ${ }^{4}$ As $\mathrm{CDH} 3$ was recently identified as the cause of congenital hypotrichosis with juvenile macular dystrophy (HJMD), which shares an overlapping hair and eye phenotype with EEM, ${ }^{6}$ we chose $\mathrm{CDH} 3$ as a candidate gene. Here we present a molecular analysis of the $\mathrm{CDH} 3$ gene and mouse expression data supporting the suggestion that $\mathrm{CDH} 3$ is the cause of EEM and is thus a yet unrecognised ectrodactyly causing gene.

\section{METHODS}

\section{Patients}

Written and informed consent was obtained from four members of family 1 and five members of family 2 . The project and the consent forms were approved by the Danish ethical committee. The remaining affected and unaffected family members could not be traced or they refused to participate in the study. In family 1 , two persons displayed limb defects. ${ }^{1}$ Their parents were first cousins. One individual had bilateral ectrodactyly with absence of middle phalanx 3 and distal phalanx 2, 3, 4 and interstitial polydactyly with two phalangeal bones articulating with metacarpal 4 on one side (fig 1). On the other side, proximal phalanx 2, 3 and middle and distal phalanx 2, 3, 4 were absent, and syndactyly occurred between fingers 4 and 5 . On the feet, syndactyly between the third and fourth toe was seen bilaterally, and between toes 1 and 2 (partial) unilaterally. The other person had unilateral syndactyly of fingers 3 and 4 and normal feet. In family 2 , the three persons with limb defects displayed different degrees of syndactyly between fingers $2 / 3,2 / 3 / 4$, or $1 / 2 / 3 / 4{ }^{4}$

\section{Molecular testing}

DNA was extracted from peripheral blood samples using standard methods. Testing for homozygosity at the $\mathrm{CDH}_{3}$ locus was carried out using microsatellite markers (D16S3107, Dl6S3025, D16S496, and Dl6S3141) spanning approximately 1.5 Mb on chromosome 16q22.1. Primers for STS markers were radioactively labelled using $\gamma-\left[{ }^{33} \mathrm{P}\right]$-dATP (Hartmann Analytic, Braunschweig, Germany) and T4-DNApolynucleotide kinase (Fermentas, Helsingborg, Sweden) according to the manufacturer's protocols. Polymerase chain reaction (PCR) was carried out using 50 ng DNA template and Taq-DNA polymerase (New England Biolabs, Beverly, MA, USA) under standard conditions according to the manufacturer's instructions, followed by separation by $5 \%$ acrylamide, $7 \mathrm{M}$ urea, $1 \times \mathrm{TBE}$ gel electrophoresis and overnight exposure to $x$ ray films. All 16 exons and exon-intron

Abbreviations: AER, apical ectodermal ridge; HJMD, congenital
hypotrichosis with juvenile macular dystrophy 
Table 1 Phenotypic spectrum of limb defects in EEM

\begin{tabular}{|c|c|c|c|c|c|c|c|}
\hline \multirow[b]{2}{*}{ Reference } & \multirow[b]{2}{*}{ Patient } & \multicolumn{5}{|l|}{ Hand $1 /$ Hand 2} & \multirow[b]{2}{*}{ Feet } \\
\hline & & Absence & Hypoplasia & Polydactyly & Syndactyly & Camptodactyly & \\
\hline $\begin{array}{l}\text { Albrectsen } \\
\text { and Svendsen' }\end{array}$ & 1 & $2 D, 3 M D, 4 D / 2 P D, 3 P D, 4 D$ & & $4 /$ & $4-5 / 3-4 /$ & & Syndactyly $1-2$ or $3-4$ \\
\hline Ohdo et al & $\begin{array}{l}1 \\
2 \\
3\end{array}$ & $\begin{array}{l}2 P M D, 3 M D / 2 P M D, 3 D, 4 M D \\
2 M D, 3 M D / 2 M D \\
2 P M D, 3 P M D, 4 P M D / 2 P M D \\
3 P M D, 4 P M D\end{array}$ & & & & $1,4,5 /$ & $\begin{array}{l}\text { Syndactyly } 3-4 \text {, split } 2 D \\
\text { Syndactyly } 3-4 \\
\text { Absence of } 2 \text { PMD or } \\
3 \text { PMD, hypoplastic } 3 \text { and } \\
4 \text {, or } 5 \text {, syndactyly } 1-2 \text { or } \\
3-4\end{array}$ \\
\hline & 4 & $2 \mathrm{PMD}, 5 \mathrm{PMD} / 2 \mathrm{PMD}, 5 \mathrm{PMD}$ & & & & & \\
\hline $\begin{array}{l}\text { Hayakawa et al } \\
\text { Balarin Silva et } a l^{4}\end{array}$ & $\begin{array}{l}1 \\
1 \\
2 \\
3^{*}\end{array}$ & $2 D, 3 D / 2 P M D, 3 M D$ & $2 \mathrm{Mc} /$ & & $\begin{array}{l}3-4 / \\
2-3 / 2-3 \\
2-3-4 / 2-3-4 \\
1-2-3-4 / 1-2- \\
3-4\end{array}$ & 2,3 & \\
\hline Senecky et $a f^{5}$ & $\begin{array}{l}1 \\
2\end{array}$ & $\begin{array}{l}2 \mathrm{D} / \\
2 \mathrm{D} /\end{array}$ & 2 nail/ & & $3-4 /$ & & \\
\hline
\end{tabular}

*Mutation carrier with no retina or hair defects.

$D$, distal phalanx; $M$, middle phalanx; Mc, metacarpal; $P$, proximal phalanx.

border regions in the $\mathrm{CDH} 3$ gene were sequenced on both strands; primers were designed in the intron regions (table 2) and amplified by PCR using Taq-DNA polymerase (New England Biolabs) according to the manufacturer's protocol. PCR conditions included an initial denaturation for $5 \mathrm{~min}$ at $94^{\circ} \mathrm{C}$, followed by 40 cycles of $30 \mathrm{~s}$ at $94^{\circ} \mathrm{C}, 30 \mathrm{~s}$ at the individual annealing temperature determined for each primer set (table 2), $45 \mathrm{~s}$ at $72^{\circ} \mathrm{C}$, and a final extension for $7 \mathrm{~min}$ at $72^{\circ} \mathrm{C}$. PCR products were separated by $2 \%$ agarose, $1 \times$ TBE gel electrophoresis. Primers were removed by treatment with $1 \mathrm{U}$ shrimp alkaline phosphatase (USB, Cleveland, OH, USA) and $10 \mathrm{U}$ exonuclease I (New England Biolabs) followed by sequencing using the BigDye Terminator Kit (Applied Biosystems, Foster City, CA, USA) and analysed on an ABI 377 sequencer (Applied Biosystems).

Mutations were confirmed with restriction enzyme digests of DNA from the families and from a minimum of 60 normal individuals (120 alleles) serving as a control group. The mutation c.965A $\rightarrow \mathrm{T}$ disrupted a BsrDI restriction site. Digestion of the PCR product of exon 7 generated by the sequencing primers (table 2) resulted in a $32 \mathrm{bp}$ and a $97 \mathrm{bp}$ fragment from a normal allele and a 129 bp fragment from the mutated allele, which were separated on a $20 \%$ acrylamide $1 \times$ TBE gel. The mutation c.829delG disrupted a BanI restriction enzyme site. Digestion products of the PCR product of exon 7 generated by the sequencing primers (table 2) were separated on a $2 \%$ agarose gel resulting in a $159 \mathrm{bp}$ and a $194 \mathrm{bp}$ fragment from a normal allele and a $353 \mathrm{bp}$ fragment from a mutated allele.

\section{In situ hybridisation}

Whole mount and section in situ hybridisation were performed as described previously using murine wildtype embryos of stages E10.5-E13.5. ${ }^{7}$ For hybridisation a 678 bp antisense probe specific for murine $C d h 3$ (Ensembl Transcript ID ENSMUST00000034383) was generated with PCR using murine embryonal cDNA and the following primers: forward 5'-TGC TGA CTA GGG GGA CAG TT-3, reverse 5'-CCC TCT CCA TCC ATG TCT GT- $3^{\prime}$. The PCR product was cloned into a TOPO TA Cloning Kit (Invitrogen, Carlsbad, CA, USA), sequenced, and transcribed using a DIG RNA labelling kit (Roche, Mannheim, Germany).

\section{RESULTS}

\section{Mutation analysis}

The initial test for homozygosity at the $C D H 3$ locus showed that all EEM patients (1.II1, 1.II2, 2.II1) displayed a

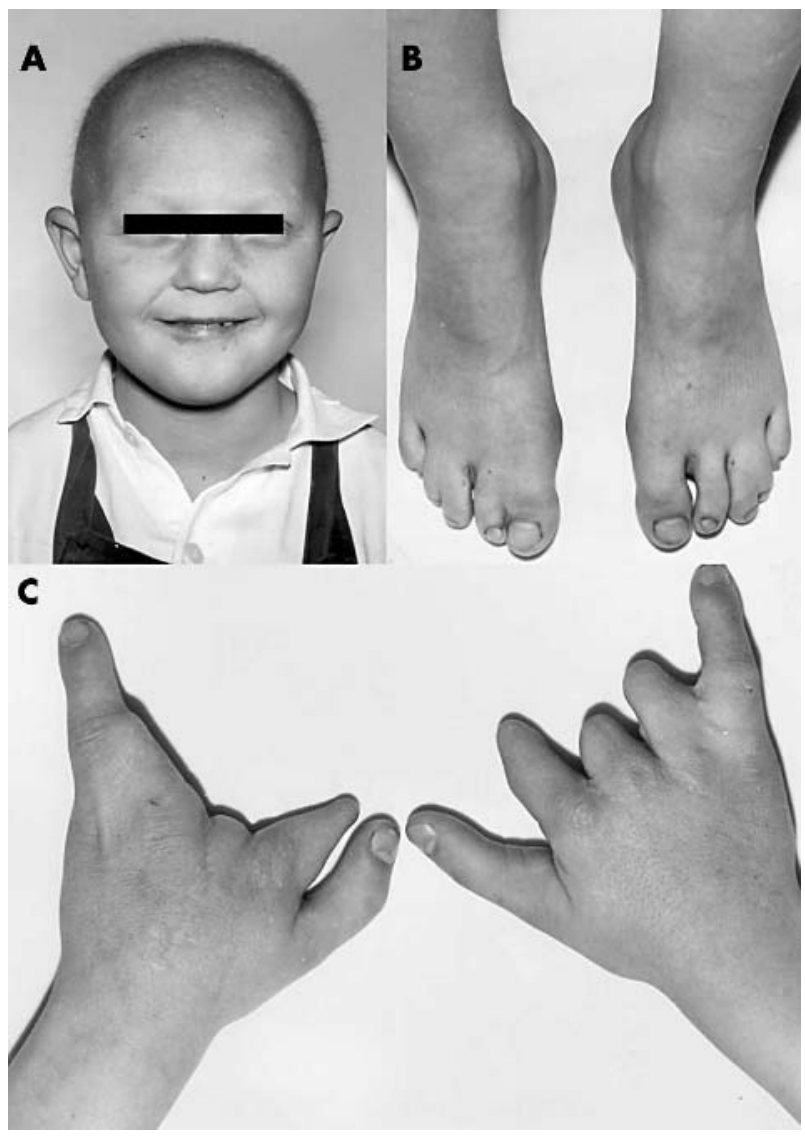

Figure 1 EEM phenotype in individual 1.III. (A) Note sparse hair. (B) Note bilateral syndactyly of toes 3 and 4 , and unilateral syndactyly of toes 1 and 2. (C) Note absence defects of fingers 2, 3, and 4, and partial syndactyly. For variability of limb malformations observed in EEM see table 1. (Photographs reproduced with permission)

homozygous haplotype, whereas all other tested family members were heterozygous (data not shown). Direct sequencing revealed homozygous mutations in both families. Patients from family 1 (fig 2A) had a missense mutation in exon $8 \quad($ c.965A $\rightarrow$ T) (fig $2 \mathrm{C}$ ) causing a change from asparagine to isoleucine at amino acid 322 (N322I) (fig 2E). The unaffected parents were both heterozygous for the mutation. This was confirmed by a BsrDI restriction site 
Table 2 Primers used for sequencing of $\mathrm{CDH} 3$

\begin{tabular}{|c|c|c|c|c|}
\hline Exon & Primer name & Primer sequence & $\begin{array}{l}\text { Length of PCR } \\
\text { fragment (bp) }\end{array}$ & $\begin{array}{l}\text { Annealing } \\
\text { temperatures }\left({ }^{\circ} \mathrm{C}\right)\end{array}$ \\
\hline \multirow[t]{2}{*}{1} & CDH3-EX1-F & GACCAATCAGCACCCACCT & 384 & 67 \\
\hline & CDH3-EX1-R & GAGGGCAGAGAGTGAAGGAG & & \\
\hline \multirow[t]{2}{*}{2} & CDH3-EX2-F & CAAGGGAGTCCCGGAAGG & 277 & 60 \\
\hline & CDH3-EX2-R & GGTCCACACCAAAATGGTCA & & \\
\hline \multirow[t]{2}{*}{3} & CDH3-EX3-F & GTCAGAGGACTCTTGTCAGTCTTG & 248 & 60 \\
\hline & CDH3-EX3-R & GCTCCTGGCCAGCAATTT & & \\
\hline \multirow[t]{2}{*}{4} & CDH3-EX4-F & AGGTGAGAGGATGTTGAGCA & 284 & 65 \\
\hline & CDH3-EX4-R & AAATCTCATGCAGGCCTITG & & \\
\hline \multirow[t]{2}{*}{5,6} & $\mathrm{CDH} 3-\mathrm{EX} 56-\mathrm{F}$ & GCCCCTCTICACAGAGGACT & 581 & 65 \\
\hline & CDH3-EX56-R & TGATACACAGCCAAGGAAATCA & & \\
\hline \multirow[t]{2}{*}{7} & CDH3-EX7-F & GTAGACAGGGCTGGAGTTGG & 353 & 68 \\
\hline & CDH3-EX7-R & ACGTGGGTCCTCACTGTTCT & & \\
\hline \multirow[t]{2}{*}{8} & $\mathrm{CDH} 3-\mathrm{EX} 8-\mathrm{F}$ & CAGTGCTTCCTGGAGGTCAG & 286 & 65 \\
\hline & CDH3-EX8-R & AGACTGGTTCCAGTITCCTGAG & & \\
\hline \multirow[t]{2}{*}{9} & CDH3-EX9-F & GTTGGATGGAGGCTTCTCAG & 360 & 65 \\
\hline & CDH3-EX9-R & GGACTAGCCCACGGTAGACA & & \\
\hline \multirow[t]{2}{*}{10} & $\mathrm{CDH} 3-\mathrm{EX} 10-\mathrm{F}$ & CACATCTCAACTGTCCTGCAC & 392 & 65 \\
\hline & CDH3-EX10-R & GAACAAACGTTGGCCATGAT & & \\
\hline \multirow[t]{2}{*}{11} & CDH3-EX11-F & TCTGCCAGTTGGTATGAGGA & 311 & 60 \\
\hline & CDH3-EX11-R & AGGAAACATGCTGTGCTGTG & & \\
\hline \multirow[t]{2}{*}{12} & $\mathrm{CDH} 3-\mathrm{EX} 12-\mathrm{F}$ & AGAGCTGGGCGGTAAACAG & 389 & 65 \\
\hline & CDH3-EX12-R & GTGTGCAGAATCCTGGTGTG & & \\
\hline \multirow[t]{2}{*}{13} & $\mathrm{CDH} 3-\mathrm{EX} 13-\mathrm{F}$ & TGTGGAAGCCGTATTCTCAA & 394 & 60 \\
\hline & CDH3-EX13-R & TGGTGGCCTCTTAGTTCCAG & & \\
\hline \multirow[t]{2}{*}{14} & $\mathrm{CDH} 3-\mathrm{EX} 14-\mathrm{F}$ & CTGCAGITAGAGGGGCTCTG & 374 & 65 \\
\hline & CDH3-EX14-R & ACCAGAGAAGTGCTGGAGGA & & \\
\hline \multirow[t]{2}{*}{15} & $\mathrm{CDH} 3-\mathrm{EX} 15-\mathrm{F}$ & TCCCCATGAGCCAGAGTATC & 390 & 65 \\
\hline & CDH3-EX15-R & GTCAAAAGCTGGTTGGTGGT & & \\
\hline \multirow[t]{2}{*}{16} & CDH3-EX16-F & GAGAGAGGGGCTCACAGAGA & 595 & 65 \\
\hline & CDH3-EX16-R & GGACACAGGGTTGAGCATTT & & \\
\hline
\end{tabular}

assay (fig 2A), which also failed to identify any mutations in 120 control alleles.

The Brazilian proband (family 2) (fig 2B) was homozygous for a deletion mutation in exon 7 (c.829delG) (fig 2D). The mutation is predicted to introduce a frameshift and a premature stop codon at amino acid residue 295 (fig 2F). Provided this mRNA is translated, it is expected to cause a non-functional protein lacking both its intracellular and membrane spanning domains and its extracellular domains 3-5 (fig 3A, B). The parents, a brother, and a son of the affected were all heterozygous for the mutation. The findings were confirmed by a BanI restriction site assay (fig 2B).

We identified different alleles in patients from family $\mathrm{l}$ and 2 by confirming two known SNPs in introns 8 and 10, and four SNPs in exons 12, 13, and 15, which were present in one family but not the other (table 3 ). Three of the latter had previously been reported (c.1623T $\rightarrow$ C, c.1689G $\rightarrow$ C, c. $1965 \mathrm{G} \rightarrow$ A), while c.224lC $\rightarrow$ A represents a novel SNP.

\section{Structure of $\mathrm{CDH} 3$ and localisation of mutations}

$\mathrm{CDH} 3$ is a classical cadherin with five extracellular cadherin repeats (ECl-5), a membrane spanning section, and a cytoplasmic domain (fig 3A,B). It is located on the long arm of chromosome 16 as part of a cluster containing five other cadherins (CDH1, CDH5, CDH8, CDH11, and CDH16) spanning $\sim 7.2 \mathrm{Mb}$ (fig 3C). By aligning the protein sequences of $\mathrm{CDH} 3$ and Xenopus $\mathrm{C}$-cadherin and identifying the correlating residues in the recently published C-cadherin structure, ${ }^{8}$ we found that amino acid residue 322 affected in family $\mathrm{l}$ is part of $\mathrm{a} \mathrm{Ca}^{2+}$ binding domain connecting EC2 and EC3 (fig 3B). The deletion in family 2 is located in EC2.

\section{Mouse in situ expression data}

At stages E10.5 and E11.5 Cdh3 is expressed during mouse embryonal development in craniofacial structures including the orofacial region, and the pharyngeal arches (fig 4A, B). Specific analysis of expression in the retina was not carried out. Cdh3 expression was also observed in the gut, the presomitic mesoderm, and to a lesser extent in the most caudal somites. At these stages $C d h 3$ is also expressed in the fore and hind limbs in the limb ectoderm including the apical ectodermal ridge (AER), and to some extent in the mesenchyme (fig 4C). When chondrogenic condensations of phalanges start to form at E12.5, Cdh3 expression is detected in the interdigital web, where it continues to be expressed at E13.5 (fig 4D, E).

\section{DISCUSSION}

Ectrodactyly occurs as an isolated trait with at least five known loci and as part of many syndromes. Mutations in TP63 have been shown in isolated split hand foot malformation (SHFM4; OMIM 605289) as well as in ectrodactyly, ectodermal dysplasia, and cleft-lip-palate (EEC3; OMIM 604292). In patients with SHFM3 (OMIM 600095), a tandem $\sim 400-550 \mathrm{~kb}$ duplication of 10q24 involves several genes including Dactylin (FBXW4), a gene known to cause ectrodactyly in mice, $L B X I$, and FBWIA. ${ }^{9}{ }^{10}$ In the present study we have identified a third gene associated with ectrodactyly and show that mutations in a cadherin can cause limb malformations in humans

Classical cadherins are $\mathrm{Ca}^{2+}$ dependent adhesion molecules acting as dimers in homophilic binding. ${ }^{11}{ }^{12}$ Their specific spatial and temporal expression patterns during embryogenesis suggest an important role in normal development. ${ }^{11}{ }^{13} 14$ In this study we have identified two distinct homozygous mutations in two families predicted to lead to loss of CDH3 function or defective $\mathrm{Ca}^{2+}$ binding. In family 2, a nonsense mutation (c.829delG) introduced a preterminal stop codon, predicting a protein lacking both its intracellular and membrane spanning sections and its extracellular domains $3-5$. Thus, this mutation very likely causes loss of function of $\mathrm{CDH}$. The missense mutation identified in both affected sibs in family $\mathrm{l}(\mathrm{c} .965 \mathrm{~A} \rightarrow \mathrm{T})$ results in substitution of the polar asparagine at position 322 with a hydrophobic isoleucine 
A
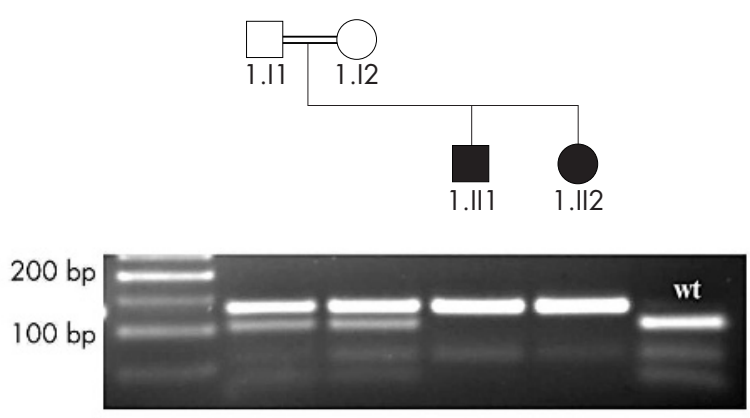

C

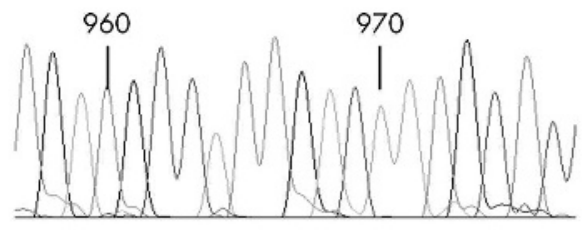

Wt TGATGCCAATGATAATGCTC Mut TGATGCCATTGATAATGCTC

E $\begin{array}{lrrr} & 320 & 330 \\ \text { Wt } & \text { AVAVVEILDA N } & \text { DNAPMFDPQK } \\ \text { Mut } & \text { AVAVVEILDA I } & \text { DNAPMFDPQK }\end{array}$

G Human (NM_001793)
Chimp (NM_001793)
Mouse (NM_007665) $C$ elegans (NM_066286)

$\mathrm{H}$ gi|14589891cadherin3
gi|4757960|cadherin1
gi|14589889|cadherin2
gi||14589893|cadherin4
x79981Cadherin5
gi||4826673|cadherin6
gi|16306487|cadherin7
AB035305Cadherin8
gi|13431362|CAD9
AF039747Cadherin10
NP_387513Cadherin11
NP_004052Cadherin12
gi|20306944|Cadherin13
gi|4826669|cadherin15
gi|4826671|cadherin18
NP_066976cadherin19
NP_114097cadherin20
gi|29570800|cadherin-1ike26
B

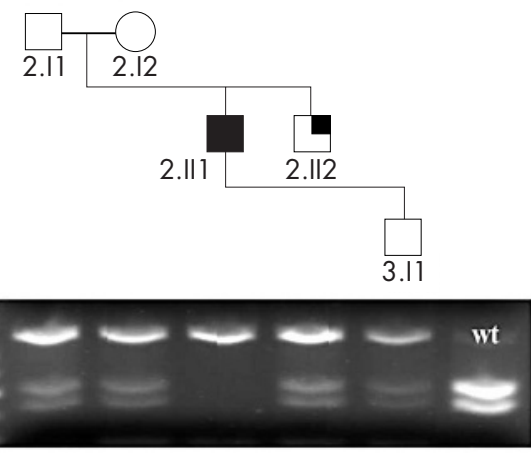

D

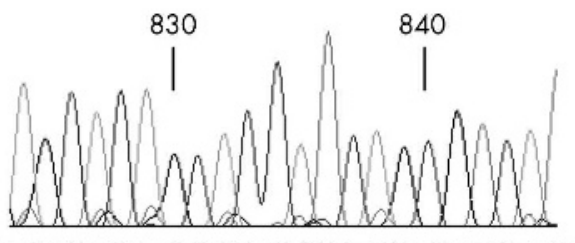

Wt AGCACAGGCACCATCAGCGTCA

Mut AGCACAGCACCATCAGCGTCA

$\mathrm{F}$

270

290

Wt FTIHRSTGTISVISSGLDREKVPEYTLTI...

Mut FTIHRSTAPSASSPVAWTGKKSLSTH 295

320

330

TTTAVAVVEILDANDNAPMFDPQKYEAHVPEN

TTTAVAVVEILDANDNAPMFDPQKYEAHVPENA

TTTAEAVVQILDANDNAPEFEPQKYEAWVPENE

STITKATIKIVDINDNSPRFDQQLYRFNVTENS

320

330

DGSTTTAVAVVEILPANDNAPMFDPQKYEAHVP EGLSTTATAVITVTPTNDNPPIFNPTTYKGOVP YGLSNTATAVITVTPVNDNPPEFTAMTFYGEVP YGLSNTATAI ITVTPVNDNPPEFTASTFAGEVP RGDSGTATVLVTLODINDNFPFFTQTKYTFVVP GGLSGTTTVNITLTDVNDNPPRFPQSTYQFKTP GGLSGTTSVTVTLTDVNDNEPRFPRRSYQYNVP GGLSGTTTLTVTLTDVNDNPPKFAQSLYHFSVP GGLSGTTTVNITLTDVNNNPPRFPQSTYQFNSP GGLSGTTTVNITLTPVNDNPPRFPONTIHLRVL GGLSGTTKVTITLTDVNDNPPKFPQSVYQMSVS GGLAGTTIVNITLTPVNDNPPRFPKS IFHLKVP VGLTGTATATIMIDDKNDHSPKFTKKEFQATVE DGLTATASAI ITLDPINDNAPEFTRDEFFMEAI GGLSGSTTVNITLTDVNDNPPRFPQKHYQLYVP GALSGTTSVLI KLSDVNDNKP IFKESLYRLTVS GGLAGTTTVNITLSPVNDNPPRFPQKHYQMSVL - - LSSTTTVHVDVQEGNNHRPAFTQENYKVQIP

$322 \mathrm{~N}$ to 1

Figure 2 Pedigree, digest results $(A, B)$, nucleotide sequences $(C, D)$, and protein sequences $(E, F)$ for family $1(A, C, E)$ and family $2(B, D, F)$. Conservation of amino acid residue 322 between species $(G)$ and between human cadherins $(H)$. In family 1 (A), digestion with the restriction enzyme BsrDI resulted in a 32 bp and a 97 bp fragment from a normal allele and a 129 bp fragment from the mutated allele. In family 2, digestion with Banl resulted in a $159 \mathrm{bp}$ and a $194 \mathrm{bp}$ fragment from a normal allele and a $353 \mathrm{bp}$ fragment from a mutated allele. 

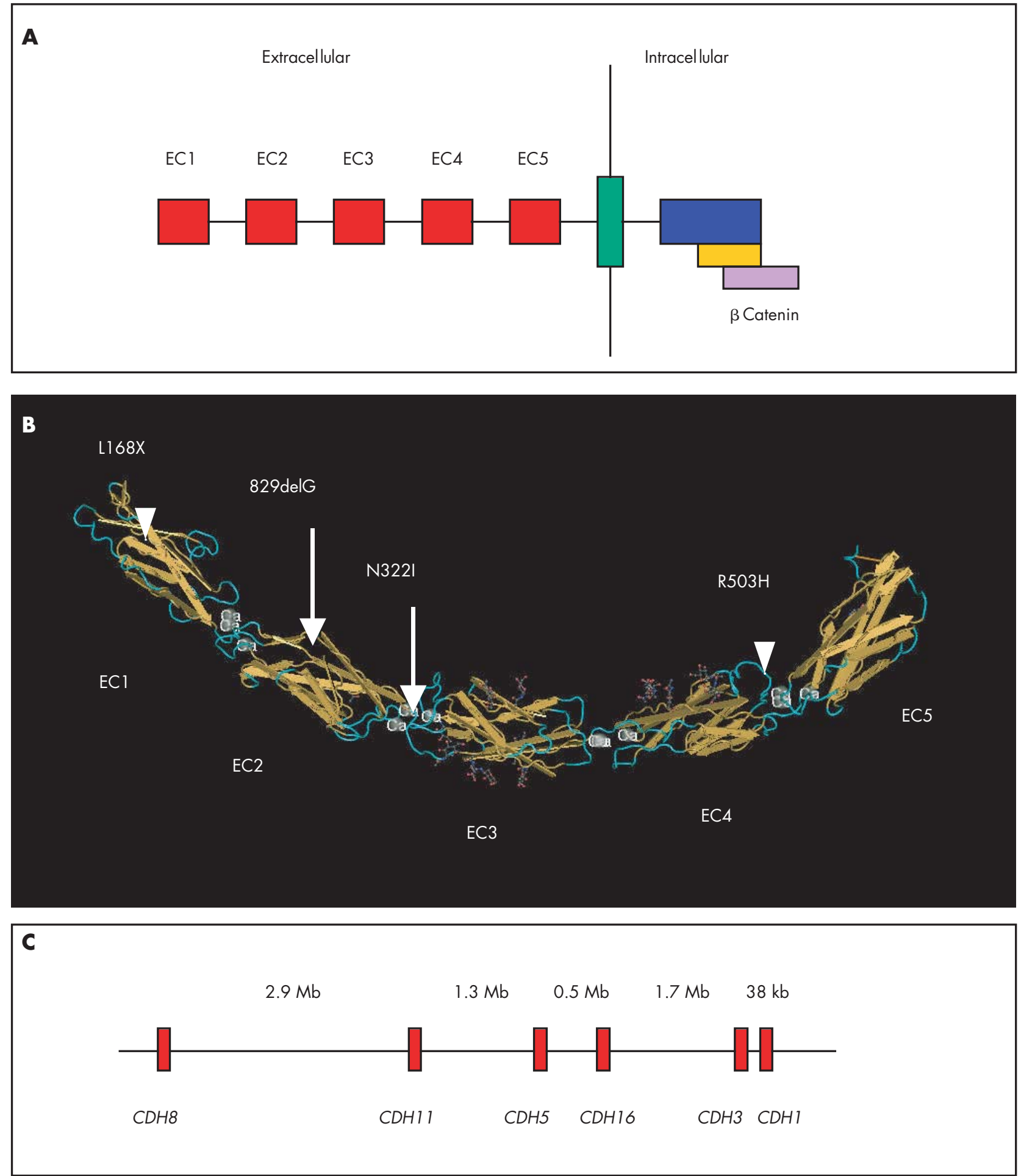

Figure 3 (A) Schematic protein structure of $\mathrm{CDH} 3$. (B) Crystal structure of the five cadherin repeat $(\mathrm{EC} 1-5)$ modules in Xenopus $\mathrm{C}$-cadherin ectodomain. Correlating sites for EEM mutations and HJMD (OMIM 601553) missense mutations are shown as predicted from alignment of CDH3 and C-cadherin. Arrows: mutations in EEM families; arrowheads: missense mutations in HJMD families. (C) Organisation of $\mathrm{CDH8}, \mathrm{CDH} 11, \mathrm{CDH5}$, $C D H 16, C D H 3$, and $C D H 1$ in a cluster on chromosome 16q.

supporting a change of function. Amino acid 322 is highly conserved in different species (fig $2 \mathrm{G}$ ) and in different human cadherins (fig $2 \mathrm{H}$ ). Functionally it is part of a motif known to bind $\mathrm{Ca}^{2+}$ located between EC2 and EC $3 .{ }^{15}$ In other cadherins the binding of $\mathrm{Ca}^{2+}$ is assumed to stabilise the extracellular structure necessary for specific cell-cell binding function and thereby affect the angle between different EC modules and the configuration of the extracellular section. ${ }^{8}$ The cytoplasmic tail of cadherins binds $\beta$ catenin, which was recently identified as linking transcription and cell adhesion by changing its distribution in the cell upon extracellular signalling from Wnts and BMP inhibitors. ${ }^{16}$ If mutations in $\mathrm{CDH} 3$ cause abnormal distribution of $\beta$ catenin in the cell, this may also be part of the pathomechanism in EEM. 
Table 3 SNPs with different alleles in Danish and Brazilian EEM patients

\begin{tabular}{|c|c|c|c|c|c|c|}
\hline Exon & Nucleotide change & Amino acid change & Type of change & SNP accession number & $\begin{array}{l}\text { Family \# 1, } \\
\text { Denmark }\end{array}$ & Family \#2, Brazil \\
\hline Ivs- 8 & Ivs8-26T $\rightarrow C$ & - & Polymorphism & rs1886697 & $\mathrm{C} / \mathrm{C}$ & $\mathrm{T} / \mathrm{T}$ \\
\hline Ivs-10 & Ivs $10+23 A \rightarrow G$ & - & Polymorphism & rs2281850 & G/G & $\mathrm{A} / \mathrm{A}$ \\
\hline \multirow[t]{2}{*}{ Ex-12 } & c. $1626 \mathrm{~T} \rightarrow \mathrm{C}$ & $\mathrm{N} 542 \mathrm{~N}$ & Synonymous & rs2296405 & $\mathrm{C} / \mathrm{C}$ & $\mathrm{T} / \mathrm{T}$ \\
\hline & c. $1689 \mathrm{G} \rightarrow \mathrm{C}$ & Q563H & Non-synonymous & rs1126933 & $\mathrm{C} / \mathrm{C}$ & $G / G$ \\
\hline Ex-13 & c. $1956 \mathrm{G} \rightarrow \mathrm{A}$ & K652K & Synonymous & rs 2274239 & $\mathrm{~A} / \mathrm{A}$ & $G / G$ \\
\hline Ex-15 & c. $2239 \mathrm{C} \rightarrow \mathrm{A}$ & R747R & Synonymous & This study & $\mathrm{A} / \mathrm{A}$ & $\mathrm{C} / \mathrm{C}$ \\
\hline
\end{tabular}

Local disruption of the AER has been suggested as the pathomechanism of ectrodactyly in patients with TP63 mutations. ${ }^{17}$ We show that $C d h 3$ is expressed in the AER from E10.5 to E12.5. Animal studies copying the EEM mutation and the phenotype will be necessary to see if loss of normal CDH3 function results in an abnormal AER or if EEM is caused by a different and as yet undefined pathogenetic mechanism. From E10.5 to E12.5 Cdh3 expression is observed to some extent in the mesenchyme, but from E13.5 it is expressed solely in the interdigital region where coordinated apoptosis will later separate the digits. The occurrence of syndactyly in hands and feet in EEM patients can be interpreted as a consequence of abnormal interdigital apoptosis. The observed expression pattern suggests that $\mathrm{CDH} 3$ plays an important and as yet unrecognised role in shaping the human hand. It is interesting that the deletion mutation in members of family 2 resulted in syndactyly but not ectrodactyly, whereas the missense mutation in family 1 resulted in both phenotypes. A study of more EEM families is necessary to determine if the variability of limb defects can be explained by a genotype-phenotype correlation. Remarkably, one individual out of four heterozygous for 829delG (2.I1, 2.I2, 2.II2, and 2.III1) presented with minimal symptoms, namely a mild bilateral syndactyly between fingers 1/2/3/4 and small and widely spaced teeth, while ophthalmological and hair examination were unremarkable. ${ }^{4}$ This suggests that subtle limb and dental defects may represent the mildest phenotype in EEM families.

Mutations in $\mathrm{CDH} 3$ were recently reported in HJMD sharing the same hair and eye phenotype as EEM ${ }^{6} 18$ (table 4). The mutations in HJMD are homozygous single base pair deletions introducing premature stop codons or missense mutations; a single family was compound heterozygous. The mutations are assumed to cause a loss of $\mathrm{CDH} 3$ function. Interestingly, the $\mathrm{R} 503 \mathrm{H}$ mutation in HJMD also affects a highly conserved amino acid directly involved in $\mathrm{Ca}^{2+}$ binding, but between EC4 and EC5. Functional differences between the cell-cell binding properties of this mutation and N322I between EC2 and EC3 seen in EEM remain to be determined.

The hair anomalies and retinal pigmentary alterations appear to be identical in HJMD and EEM, but EEM patients are additionally characterised by ectrodactyly or syndactyly (table 1) and oligodontia, enamel hypoplasia, and widely spaced teeth. ${ }^{2}{ }^{4}$ The identified deletion (829delG) was previously found in a Turkish HJMD family with associated keratosis pilaris ${ }^{19}$ indicating that a simple genotype-phenotype correlation is not sufficient. EEM and HJMD may instead belong to a single broad phenotypic spectrum where pleiotropic differences are determined by stochastic factors. However, the fact that no EEM family members display the limited HJMD phenotype may suggest that genetic factors and not stochastics are responsible.

Though speculative, it is possible that $\mathrm{CDH}_{3}$ loss of function causes HJMD, which is then modified by another gene to cause EEM. Since no EEM family member displays HJMD, the designated modifier has to segregate together with $C D H 3$. A candidate gene for this is CDHI (E-cadherin) located only $38 \mathrm{~kb}$ telomeric from $\mathrm{CDH} 3$ and known to have redundant functions. The peculiar hair phenotype occurs in hair matrix cells where only $C D H 3$ and not $C D H 1$ is expressed and no defects occur in tissues where the two cadherins are expressed together. ${ }^{6}$

In this context it is notable that animal models indicate the importance of $\mathrm{Cdh} 3$ and redundance of other genes during epithelial morphogenesis and integrity. For example, $C d h 3$
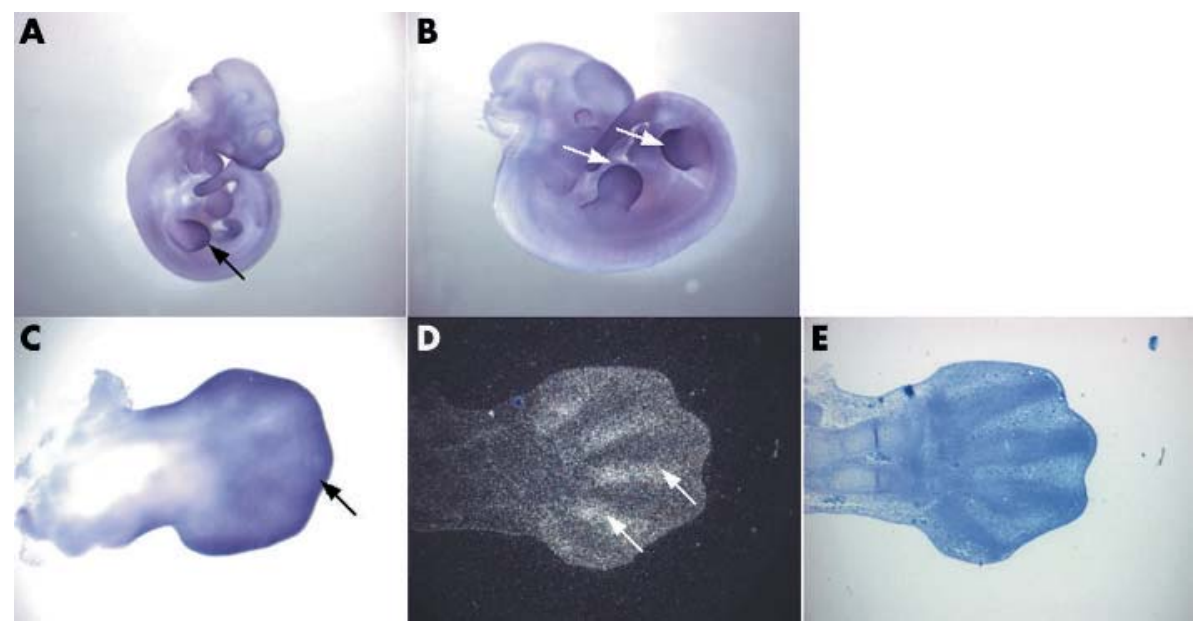

Figure 4 In situ expression analysis of Cdh3 during mouse embryonal development. (A) Expression at E10.5, (B) at E1 1.5, and (C) at E12.5 (expression in blue). (D) Expression at E13.5 (expression in white); (E) Toluidine blue counter staining. Expression in the AER is seen up to E12.5 and interdigital expression at E12.5 and E13.5 when digital condensations have occurred. Expression in limb buds, AER, and interdigital mesenchyme is marked by arrows. 
Table $4 \mathrm{CDH} 3$ mutations and phenotypic variability

\begin{tabular}{|c|c|c|c|c|c|}
\hline Exon & Nucleotide change & Amino acid change & Origin & Phenotype & Reference \\
\hline $\begin{array}{l}\text { Ex-5 } \\
\text { Ex-5 } \\
\text { Ex-7 } \\
\text { Ex-7 } \\
\text { Ex-8 } \\
\text { Ex-8 } \\
\text { Ex-11 } \\
\text { Ex-14 }\end{array}$ & $\begin{array}{l}\text { c. } 503 \mathrm{~T} \rightarrow \mathrm{A} \\
\text { c. } 462 \mathrm{delT} \\
\text { c. } 829 \mathrm{delG} \\
\text { c. } 829 \mathrm{delG} \\
\text { c. } 981 \mathrm{delG} \\
\text { c. } 965 \mathrm{~A} \rightarrow \mathrm{T} \\
\text { c. } 1508 \mathrm{G} \rightarrow \mathrm{A} \\
\text { c. } 2112 \mathrm{delG}\end{array}$ & $\begin{array}{l}\text { L168X } \\
\text { P154fsX159 } \\
\text { G277fsX295 } \\
\text { G277fsX295 } \\
\text { M327fsX348 } \\
\text { N322I } \\
\text { R503H } \\
\text { E704fsX757 }\end{array}$ & $\begin{array}{l}\text { French } \\
\text { Turkish } \\
\text { Brazilian } \\
\text { Turkish } \\
\text { Druze } \\
\text { Danish } \\
\text { Arab Israeli } \\
\text { French }\end{array}$ & $\begin{array}{l}\text { HJMD } \\
\text { HJMD } \\
\text { EEM } \\
\text { HJMD } \\
\text { HJMD } \\
\text { EEM } \\
\text { HJMD } \\
\text { HJMD }\end{array}$ & $\begin{array}{l}\text { Indelman et } a l^{19} \\
\text { Indelman et } a l^{19} \\
\text { This study } \\
\text { Indelman et }\left.a\right|^{19} \\
\text { Sprecher et } a l^{\beta} \\
\text { This study } \\
\text { Indelman et } a l^{819} \\
\text { Indelman et } a l^{19}\end{array}$ \\
\hline
\end{tabular}

knock out mice display perturbation of mammary gland development, but no defects in hair, limb, or eye morphogenesis. ${ }^{20}$ In Caenorhabditis elegans loss of Cdh3 function results in defects at the tip of the nematode tail. ${ }^{21}$ Such phenotypic differences compared to humans carrying mutations in orthologous genes are not uncommon, and may be caused by expression differences and redundant functions of other cadherins.

In conclusion, $\mathrm{CDH} 3$ represents a third gene associated with ectrodactyly and plays an important and hitherto unrecognised role in shaping the human hand. Future studies to better define the role of $\mathrm{CDH} 3$ in epithelial mesenchymal interactions may help to better characterise its function during development of the ectoderm and limb morphogenesis.

\section{ACKNOWLEDGEMENTS}

We thank the families for participating in this study, and Dr Jordão Correa for establishing contact with the Brazilian family. We are indebted to Flemming Skovby, Department of Clinical Genetics, Copenhagen University Hospital for permission to publish the clinical pictures.

\section{Authors' affiliations}

K W Kjaer, L Hansen, N Tommerup, Wilhelm Johannsen Centre for Functional Genome Research, Institute of Medical Biochemistry and Genetics, University of Copenhagen, Copenhagen, Denmark G C Schwabe, S Mundlos, Max Planck Institute for Molecular Genetics, Berlin, Germany

S Mundlos, Institute for Medical Genetics, Charité, Berlin, Germany A P Marques-de-Faria, Department of Medical Genetics, State University of Campinas School of Medicine, Campinas, SP, Brazil H Eiberg, Institute of Medical Biochemistry and Genetics, University of Copenhagen, Copenhagen, Denmark

T Rosenberg, Gordon Norrie Centre for Genetic Eye Diseases, National Eye Clinic for the Visually Impaired, Hellerup, Denmark G C Schwabe, Department of Endocrinology, Children's Hospital Charité, Berlin, Germany

The Wilhelm Johannsen Centre for Functional Genome Research is funded by the National Danish Research Foundation.

Competing interests: none declared

\section{REFERENCES}

1 Albrectsen B, Svendsen IB. Hypotrichosis, syndactyly, and retinal degeneration in two siblings. Acta Derm Venerol 1956;1:96-101.

2 Ohdo S, Hirayama K, Terawaki T. Association of ectodermal dysplasia, ectrodactyly, and macular dystrophy: the EEM syndrome. J Med Genet 1983;20:52-7.
3 Hayakawa M, Yanashima K, Kato K, Nakajima A, Yamauchi H. Association of ectodermal dysplasia, ectrodactyly and macular dystrophy: EEM syndrome (case report). Ophthalmic Paediatr Genet 1989;10(4):287-92.

4 Balarin Silva V, Simoes AM, Marques-de-Faria AP. EEM syndrome: report of a family and results of a ten-year follow-up. Ophthalmic Genet 1999;20(2):95-9.

5 Senecky Y, Halpern GJ, Inbar D, Attias J, Shohat M. Ectodermal dysplasia, ectrodactyly and macular dystrophy (EEM syndrome) in siblings. Am J Med Genet 2001;101:195-7.

6 Sprecher E, Bergman R, Richard G. Hypotrichosis with juvenile macular dystrophy is caused by a mutation in $C D H 3$, encoding P-cadherin. Nat Genet 2001;29:134-6.

7 Schwabe GC, Trepczik B, Suring K, Brieske N, Tucker AS, Sharpe PT, Minami Y, Mundlos S. Ror2 knockout mouse as a model for the developmental pathology of autosomal recessive Robinow syndrome. Dev Dyn 2004;229:400-10

8 Boggon TJ, Murray J, Chappuis-Flament S, Wong E, Gumbiner BM, Shapiro L. C-Cadherin ectodomain structure and implications for cell adhesion mechanisms. Science 2002;296:1308-13.

9 de Mollerat XJ, Gurrieri F, Morgan CT, Sangiorgi E, Everman DB, Gaspari P, Amiel J, Bamshad MJ, Lyle R, Blouin JL, Allanson JE, Le Marec B, Wilson M, Braverman NE, Radhakrishna U, Delozier-Blanchet C, Abbott A, Elghouzzi V, Antonarakis S, Stevenson RE, Munnich A, Neri G, Schwartz CE. A genomic rearrangement resulting in a tandem duplication is associated with split handsplit foot malformation 3 (SHFM3) at 10q24. Hum Mol Genet 2003;12(16):1959-71.

10 Basel D, DePaepe A, Kilpatrick MW, Tsipouras P. Split hand foot malformation is associated with a reduced level of Dactylin gene expression. Clin Genet 2003;64(4):350-4

11 Nose A, Takeichi M. A novel cadherin cell adhesion molecule: its expression patterns associated with implantation and organogenesis in mouse embryos. J Cell Biol 1986;103:2649-58.

12 Shimoyama Y, Yoshida T, Terada M, Shimosato Y, Abe O, Hirohashi S. Molecular cloning of a human $\mathrm{Ca}^{2+}$-dependent cell-cell adhesion molecule homologous to mouse placental cadherin: its low expression in human placental tissues. J Cell Biol 1989;109:1787-94.

13 Xu L, Overbeek PA, Reneker LW. Systematic analysis of E-, N- and P-cadherin expression in mouse eye development. Exp Eye Res 2002;74:753-60.

14 Palacios J, Benito N, Berraquero R, Pizarro A, Cano A, Gamallo C. Differential spatiotemporal expression of $\mathrm{E}$ - and P-cadherin during mouse tooth development. Int J Dev Biol 1995;39(4):663-6.

15 Takeichi M. Cadherins: a molecular family important in selective cell-cell adhesion. Annu Rev Biochem 1990;59:237-52.

16 Jamora C, DasGupta R, Kocieniewski P, Fuchs E. Links between signal transduction, transcription and adhesion in epithelial bud development Nature 2003;422:317-22.

17 Duijf PHG, van Bokhovej H, Brunner HG. Pathogenesis of split-hand/split-foot malformation. Hum Mol Genet 2003;12:R51-60.

18 Indelman $M$, Bergman R, Lurie R, Richard G, Miller B, Petronius D, Ciubutaro D, Leibu R, Sprecher E. A missense mutation in $\mathrm{CDH} 3$, encoding PCadherin, causes hypotrichosis with juvenile macular dystrophy. J Invest Derm 2002;119(5):1210-3

19 Indelman $M$, Hamel CP, Bergman R, Nischal KK, Thompson D, Surget MO, Ramon M, Ganthos H, Miller B, Richard G, Lurie R, Leibu R, Russel-Eggitt I, Sprecher E. Phenotypic diversity and mutation spectrum in hypotrichosis with juvenile macular dystrophy. J Invest Dermatol 2003;121(5):1217-20.

20 Radice GL, Ferreira-Cornwell MC, Robinson SD, Rayburn H, Chodosh LA, Tekeichi M, Hynes RO. Precocious mammary gland development in Pcadherin-deficient mice. J Cell Biol 1997;139(4):1025-32.

21 Pettitt J, Wood WB, Plasterk RH. Cdh-3, a gene encoding a member of the cadherin superfamily, functions in epithelial cell morphogenesis in Caenorhabditis elegans. Development 1996;122(12):4149-57. 